\title{
SMALL ENGINE, SMALL MARKET
}

\section{Dear Reader,}

The BMW i3 is the first series-production electric vehicle that can also be optionally equipped with a range extender at least as far as the serial integration of the internal combustion engine is concerned. The Munich-based car maker is not expecting production volumes to be particularly high. Experts at BMW estimate that, of the 40,000 customers a year who are expected to buy this electric car, only $10 \%$, or 4,000 , worldwide will order the range extender. Based on an average model cycle of seven years, this will mean less than 30,000 range extender units that BMW will manufacture for the i3 in total. One might indeed ask whether the development and application costs for the range extender are worthwhile for this small production volume. Economies of scale in manufacturing are hardly likely with such mini series. BMW at least has the advantage that it can use its own two-cylinder motor cycle engine as a basis. Nevertheless, the company is charging an additional price of around 4,500 euros for the range extender - quite a hefty sum if one calculates the actual benefit for the end customer. A further negative aspect, besides extra weight and maintenance, is that the engine takes up space in the vehicle.

Overall, the total market for range extender powertrains will remain relatively limited. If two million electric cars are really going to be on the world's roads in 2020 - a figure that is questionable anyway - 200,000 of these at most will be equipped with a serial range extender, and probably a lot fewer than that. This total figure will also be further divided over different regions, different technical solutions and, of course, individual market players. Another marketlimiting factor will be advances in battery technology. Higher performance and constantly falling costs of batteries may mean that, from 2020, the range extender will lose further ground in a cost-benefit comparison. But the biggest competitor for the range extender powertrain is the plug-in hybrid, which also has zero emissions locally and is even more suitable for long-distance driving. It satisfies the mobility requirements of a broad carbuying public and will have corresponding production volumes - resulting in economies of scale. By contrast, companies working on range extender systems will have to adapt to a very limited market with low production volumes. The real challenge will be to provide economically attractive products and still earn money from them in the end.

Best regards,

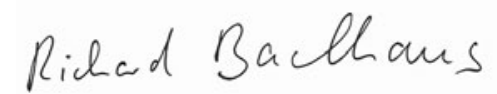

RICHARD BACKHAUS,

Vice-Editor in Chief

Wiesbaden, 30 January 2014

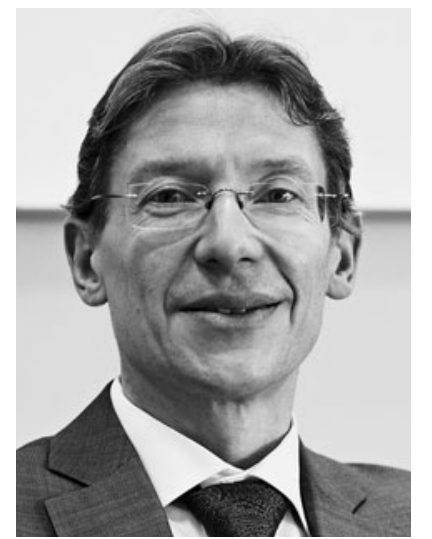

